\title{
Characterization of copper microelectrodes, following a homemade lithography, technique, and gold electroless deposition
}

\author{
Marco Antonio Rodriguez Martinez ${ }^{1,2}$, Lizbet Leon Felix ${ }^{1,2}$, \\ Luis de los Santos Valladares ${ }^{3}$, Angel Bustamante Dominguez ${ }^{2}$, \\ Jose Antonio Huamani Coaquira ${ }^{1}$, Jorge Rojas Alvarado², Yutaka Majima ${ }^{4}$, \\ Jose Albino Aguiar ${ }^{5}$, Crispin Barnes ${ }^{3}$
}

\author{
${ }^{1}$ Núcleo de Física Aplicada, Instituto de Física, Universidade de Brasília, Brasília, DF 70910-900, Brazil. \\ e-mail: fisicorodriguez@gmail.com \\ ${ }^{2}$ Laboratorio de Cerámicos y Nanomateriales, Facultad de Ciencias Físicas, Universidad Nacional Mayor de San Marcos, \\ Ap. Postal 14-0149, Lima, Perú. \\ ${ }^{3}$ Cavendish Laboratory, Department of Physics, University of Cambridge, J.J. Thomson Avenue, Cambridge CB3 OHE, \\ United Kingdom. \\ ${ }^{4}$ Materials and Structures Laboratory, Tokyo Institute of Technology, Nagatsuta-cho, Modori-ku 4259-R3-5, Kanagawa \\ 226-8503, Yokohama City, Japan. \\ ${ }^{5}$ Laboratório de Supercondutividade e Materiais Avançados, Departamento de Física, Universidade Federal de Pernam- \\ buco 50760-901, Recife, Brazil. \\ e-mail: lizbetlf@gmail.com, luis_d_v@hotmail.com, angelbd1@gmail.com, darkger@hotmail.com, majima@msl.ti- \\ tech.ac.jp, j.albino.aguiar@gmail.com, coaquira.ja@gmail.com, chwb101@cam.ac.uk
}

\begin{abstract}
We report the fabrication and characterization of copper microelectrodes obtained by a homemade lithography technique and after gold electroless deposition. For the fabrication, planes consisting of arrays of electrodes (black in color) with bow tie shape were designed and printed on a transparent paper (Canson ltd.). Using an embroidery frame with a silk fabric, a photographic emulsion was spread on the silk and simultaneously pressing the Canson paper on it. The system was introduced into a closed box and exposed with a UV light. The designed electrode templates prevented direct exposition of the UV light over copper films and indelible ink was spread over it. After the ink was dried, the copper film is immersed into ferric acid to attack the uncovered copper parts (where there is no ink). In this way, we obtained copper electrodes with initial gap separation of $\sim 142 \mu \mathrm{m}$ and subsequently, they followed electroless deposition of gold to make the copper electrodes to contact. For the characterization, electrical measurements were performed. They present ohmic resistance values in the order of $10^{6} \Omega$ produced by surface scattering of the electrons within the gold microwire and enhanced by oxidation of the copper electrodes.
\end{abstract}

Keywords: copper microelectrodes, electroless deposition, ohmic behavior, oxidation process.

\section{INTRODUCTION}

Currently, the fabrication of symmetrical metal electrodes separated by a few nanometers is of great importance for micro- ,nano- and molecular-electronics [1]. Different type of molecules, crystals, DNA, proteins and other nanostructures have been placed in the nanogap electrodes to pursue next generation of nano-devices [2-10]. For this purpose, during the last two decades, a lot of efforts have been devoted to develop techniques for obtaining micro- and nanogap electrodes. Techniques such as mechanical break junction [4,11], electromigration-induced break junction (EIBJ technique) [5,12], and electrodeposition [14-16] have been developed. Recently, a clever experiment has been performed by Y. Majima [17] and his group to obtain gold nanogaps electrodes. They have achieved nanogaps by a simply immersion of the electrodes in a common medical liquid based on electroless deposition avoiding the use of electrochemical cells. 
For electroless plating, gold salts such as $\mathrm{KAu}(\mathrm{CN})_{2}, \mathrm{Na}_{3} \mathrm{Au}\left(\mathrm{SO}_{3}\right)_{2}$, and $\mathrm{HAuCl}_{4}$ are commonly used [18]. However, these solutions, particularly those containing cyanide materials, should be handled with sufficient care to prevent the generation of highly toxic hydrocyanic acid gases. For this reason, innocuous gold electroless solutions are preferred for the protection of health and environment. Regarding the metal electrodes surface, the most preferable is gold [17] since it allows the deposition of other different metals because it is a good conductor and it prevents oxidation. Nevertheless, other cheaper materials, such as copper, have not been much investigated for growing nanogaps electrodes.

In this work we report a homemade lithography technique for the fabrication of copper electrode pairs and their electroless deposition with gold. We have achieved gold deposition on the cooper electrodes surface until a contact is formed. We demonstrate that it is possible to electroless deposit gold on copper electrodes and to put them into contact. This happened in spite that the initial distance gap obtained by our homemade lithography is thousand times larger than the average distance achieved by other sophisticated techniques [12]. In addition, our technique allows fabricating relative large area electrodes $(3.2 \mathrm{~cm} \mathrm{x} 2.2 \mathrm{~cm})$ than common lithography $\left(1 \times 1 \mathrm{~mm}^{2}\right)[12,19]$. In our case, the area of the electrodes can be reduced by fine and selected cuts. Technological advantages lie in having obtained micro gaps that can be used to place micro or macromolecules. Also nanogaps could probably get through the application of techniques for breaking our microwire as is the electromigration-induced break junction (EIBJ technique).

\section{MATERIALS AND METHODS}

\subsection{Fabrication of initial electrodes by a homemade lithography}

We have performed a homemade lithography process without the use of any sophisticate equipment. With the help of the Corel Draw software, planes of array of electrodes with bow tie shape $(5 \mathrm{~cm} \times 4 \mathrm{~cm})$ were designed. The planes were printed on a transparent paper (Canson ltd.) to allow transmittance of the natural light through it. Using an embroidery frame with a silk fabric divided into 100 to 150 lines per inch, the electrode paths were painted. We used a photo-sensible green film made by the company Rednora, which allows exposure range from 365 to $400 \mathrm{~nm}$ and with thickness of 40 micrometers and a resolution of 60 micrometers. This film hardens when it is exposed to UV. The photosensible film is spread across the surface of the silk fabric, and the Canson paper was pressed over this. Then the silk fabric and the Canson paper with the film between them were introduced into a closed box in which a UV light source exposed the system around 10 to 15 minutes as shown in Figure 1(a). The black printing designs of the electrodes prevent exposition of the UV light over them. In fact, this color has a quite high absorption coefficient and does not allow the passage of UV rays; therefore, these parts are removed easily leaving the design on the silk fabric as shown in Figure 1(b).

Then, the silk fabric containing the designs was placed on a copper ( $1 \mathrm{~mm}$ thickness) /pertinax $(\mathrm{Cu} / \mathrm{FR}-2)$ substrate as shown in Figure 1(c) and indelible ink was spread over it. Eventually, after the ink was dried, the copper film is immersed in ferric acid $\left(\mathrm{FeO}_{4}\right)^{2-}$ to attack the uncovered copper parts (where there is no ink). The time for the removal of the copper leaving the pertinax (FR-2) was around 8 minutes. In this way we obtain films consisting of copper electrode arrays on FR-2 substrates (see Fig. 1(d)) 


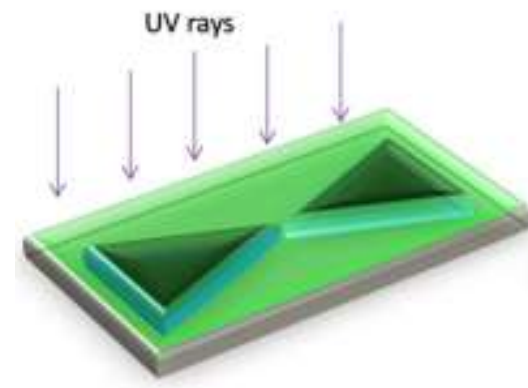

a)

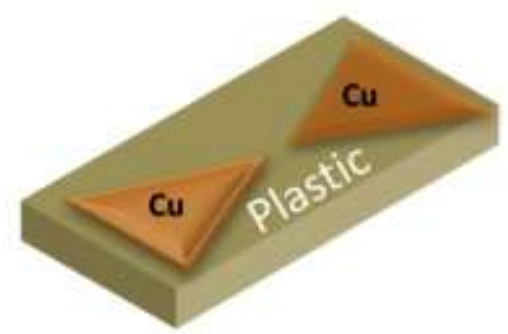

d)

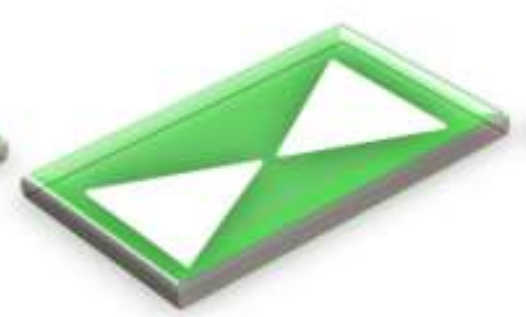

b)

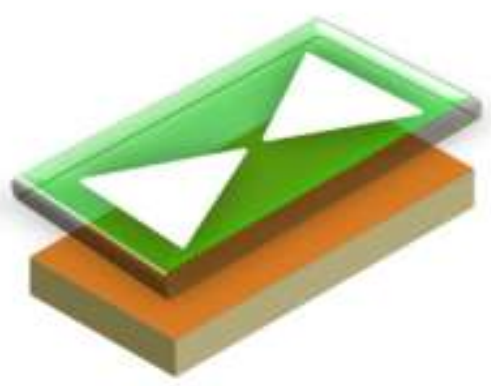

c)

Figure 1: a)-d) Schematic representation of the homemade lithographic technique process to obtain copper microgaps electrodes and e) their electroless deposition with gold.

\subsection{Electroless gold deposition}

The gold electroless deposition technique of the electrodes is described in detail in a previous work [16] with some modifications in the electrolyte composition and the steps followed during the plating process. In brief, the electroless plating solution was based on a combination of iodine tincture, gold, and $\mathrm{L}(+)$-ascorbic acid. Iodine tincture reacts with gold film to form $\left[\mathrm{AuI}_{4}\right]^{-}$and the ascorbic acid reduces excess $\mathrm{I}_{3}{ }_{3}$ to $\mathrm{I}^{-}$and the $\mathrm{Au}$ (III) complex to $\mathrm{Au}$ on the $\mathrm{Cu}$ surface [17]. During this process, some gold crystals of different sizes remain undissolved in the electrolyte. Some images of these undissolved gold particles are shown in Fig. 2. Since $\mathrm{Cu}_{2} \mathrm{O}$ and $\mathrm{CuO}$ are formed on $\mathrm{Cu}$ surfaces in ambient conditions [20], prior electroless deposition the $\mathrm{Cu}$ electrodes were immersed into $10 \mathrm{ml}$ of hydrochloric acid $(\mathrm{HCl})$, with concentration of $2.5 \%$, for $30 \mathrm{~s}$ so as to remove these $\mathrm{Cu}$-oxides. We also observed that higher concentration of $\mathrm{HCl}$ promotes etching of the copper film. Immediately, the electrodes were rinsed with distilled water following dropping the plating solution directly to the gap electrodes (as shown in Fig. 1(e) above).

\subsection{Characterization}

The structural properties of the copper electrodes were studied by X-ray diffraction (XRD) using a commercial diffractometer (Bruker D 8 Focus) with $\mathrm{Cu} \mathrm{K \alpha}$ radiation. The diffractograms were recorded in the 20 range from $35^{\circ}$ to $100^{\circ}$ and a step size of $0.02^{\circ}$. For the electrical characterization, we performed current-voltage (IV) measurements by the four probe method using an electrometer (Keithley, model 2400) and a homemade set up, demonstrating that the gold electrodes are stable at room temperature and in air. The images of the samples before and after gold deposition were taken with a light microscope Carl Zeiss Primo Star and its digital camera Canon PowerShot 6.9. 

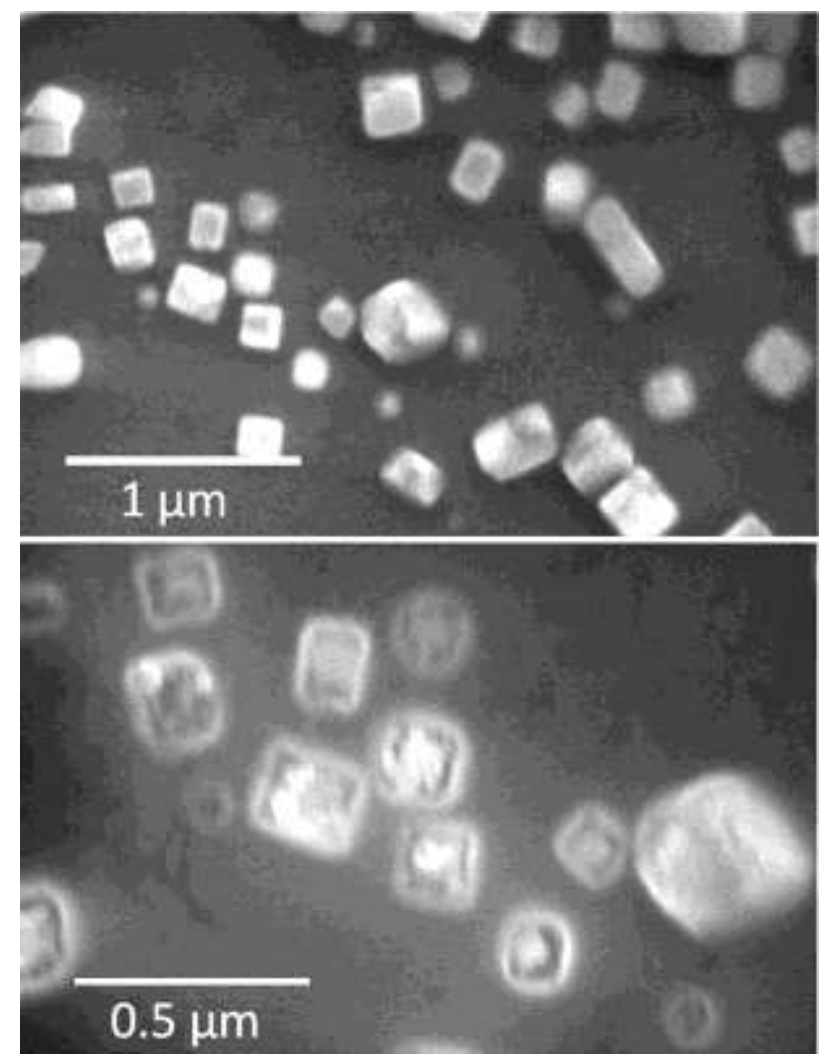

Figure 2: Scanning electron micrographs (at two magnifications) of some undissolved gold crystals used for the electroless platting.

\section{RESULTS AND DISCUSSION}

Figure 3 shows the X-ray diffraction patterns of the copper electrodes taken after $\mathrm{HCl}$ washing and prior gold electroless plating. All Bragg reflections in the XRD are consistent with the cubic structure of the copper phase (space group, $P m \overline{3} m$ ), excluding the occurrence of $\mathrm{Cu}$-oxides. In order to estimate the particle size, the XRD pattern was refined by using the Rietveld method. The particle size (D) is related to the line-width $(\Gamma)$ by the Scherrer equation: $D=0.916 \lambda / \Gamma \cdot \cos \theta_{h k l}$, where $\lambda$ is the wavelength of the X-rays $(0.15418 \mathrm{~nm})$, and $\theta_{h k l}$ is the Bragg's angle. The average crystallite sizes $\langle D\rangle_{X R D}=(87 \pm 0.1) \mathrm{nm}$ is estimated. 


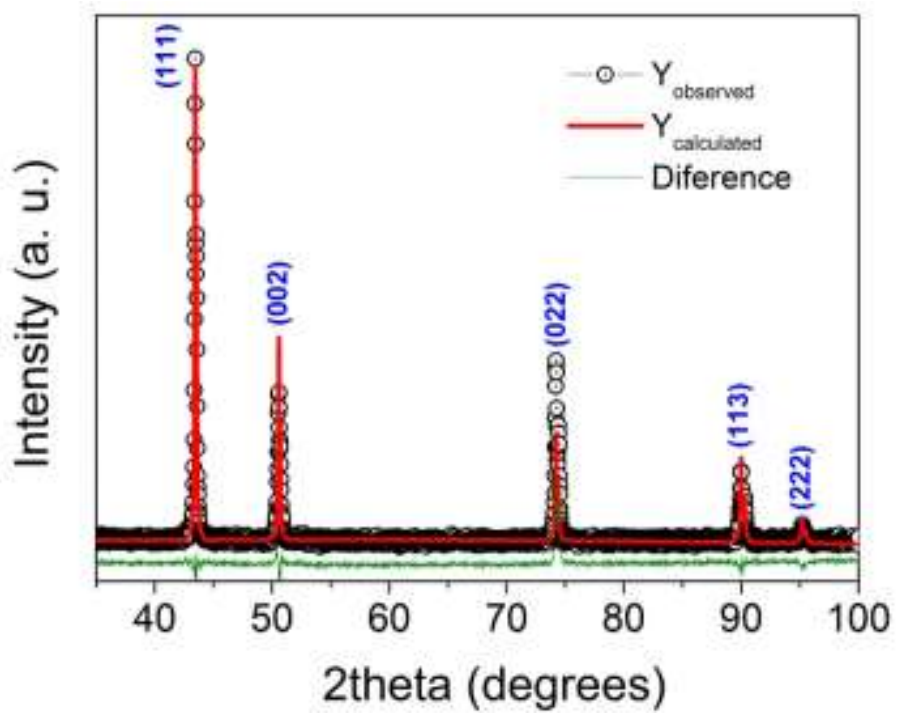

Figure 3: XRD patterns of the initial copper electrodes. The observed and calculated data are represented by the points and solid line, respectively. The calculation was performed by following the Rietveld method. The difference between the observed and calculated data is also plotted (green lines).

Figure 4 shows optical microscope images of the superficial morphology of the copper electrodes before and after gold electroless plating. Fig. 4(A) shows the $\mathrm{Cu}$ electrodes after $\mathrm{HCl}$ bathing (before electroless plating). It is demonstrated that our homemade lithographical technique is effective to obtain copper electrodes of $1 \mathrm{~mm}$ thickness forming gaps up to $142.38 \mu \mathrm{m}$ and without the use of any sophisticate equipment. After gold electroless deposition (Fig. 4(B)), we observe parallelepiped gold crystals bridging the copper electrodes. The gold crystals have different sizes (from $50 \mathrm{~nm}$ to $10 \mu \mathrm{m}$, see also Fig. 2) $\mu \mathrm{m}$ and we observed that up to three crystals arrange vertically, thus the thickness of the gold coating is in the interval 1-100 $\mu \mathrm{m}$. Our research group is currently investigating the improvement of the technique to obtain a more uniform electroless platting. The adherence of the gold coating on the copper substrate was confirmed by washing the samples in $\mathrm{H}_{2} \mathrm{O}$ and $\mathrm{C}_{3} \mathrm{H}_{7} \mathrm{OH}$ several times.

The deposition of gold on copper is mediated by the action of the $\mathrm{L}(+)$-ascorbic acid, which enhance oxidation catalysis of the copper surface while reducing gold ions on to the surface. This process yields the adherence of $\mathrm{Au}$ on $\mathrm{Cu}$ through a superficial electrostatic equilibrium. The oxidation catalysis occurs in the same way such as on gold but a lower rate $[16,22]$. It is woth mentioning that it is possible that at the time of immersing the copper/pertinax substrate to ferric acid there was a microscopic detachment of pertinax particles leaving exposed $\mathrm{Cu}$ points as seen in Figure 4(A). For this reason the deposit of Au nanoparticles can occur in both cases, $\mathrm{Cu}$ points as the edges of the electrodes as shown in Figure 4(B). We evaluated in between 87 pairs of copper electrodes among which were excluded 13 broken initial pairs of electrodes due to homemade lithography technique failure obtaining microgaps with separations of less than 160 and $120 \mu \mathrm{m}$ with process yield of $62 \%$ (46/74) and 38\% (28/74) respectively. After gold plating bath, we obtained to bridge the copper electrodes with process yield of 59\% (27/46) and 75\% (21/28) in the same order. 


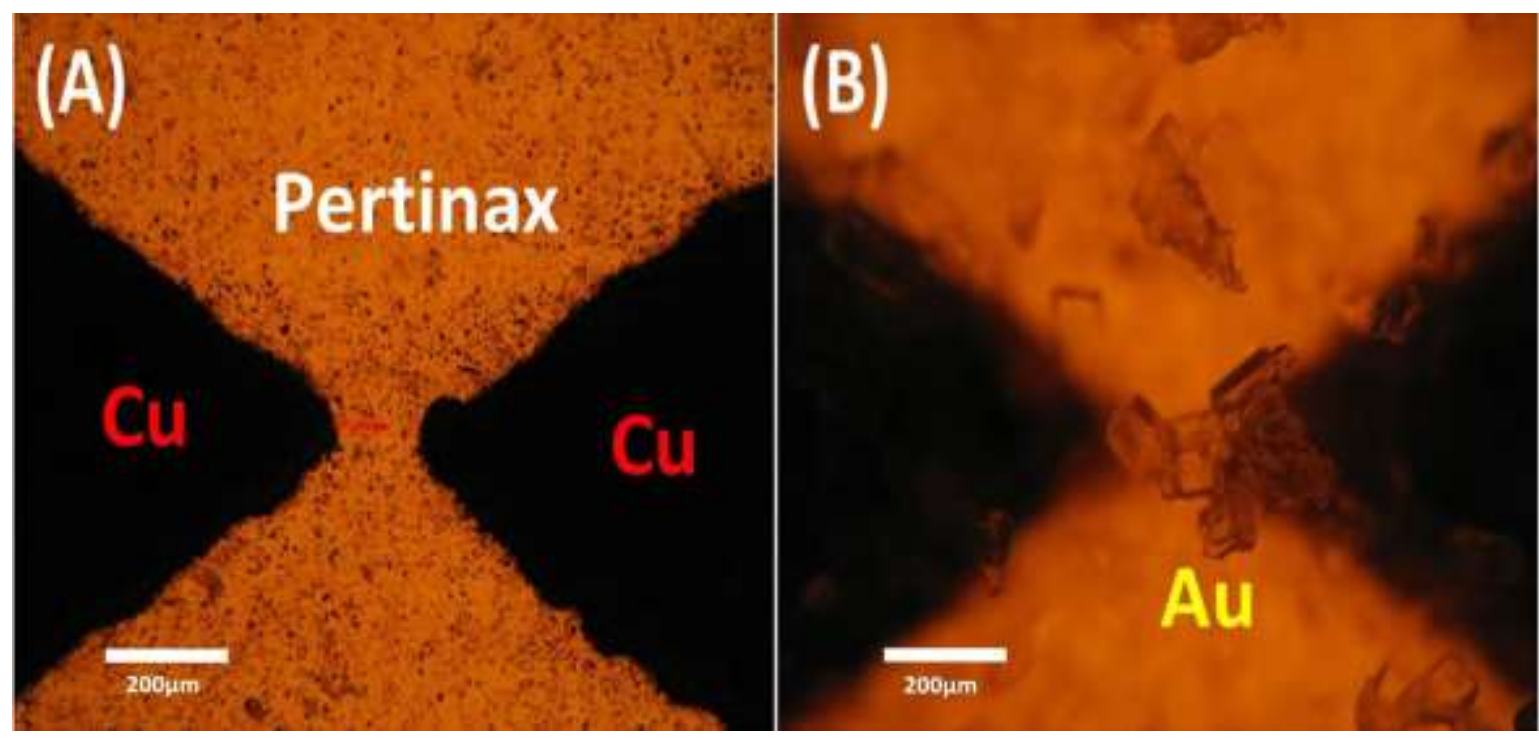

Figure 4: Optical images of a typical sample obtained by our homemade lithographical technique before (A) and after (B) electroless gold plating.

Figure 5 shows the I-V measurements performed by the four probe method at room temperature of one arbitrary pair of copper electrodes bridged with gold crystals. It is well known that the conductance of a wire is inversely proportional to its length and that the electron transport mechanism depends of length scale. In the present work, the length (L) of the gold microwire formed between the copper electrodes is $\sim 142 \mu \mathrm{m}$ and comparing to his respective mean free path $(\ell)$ at room temperature, we obtain that $\mathrm{L}>>\ell$ which means it consists on a diffusive electron transport [23]. This is confirmed by the ohmic trace obtained in the devices in this work (see Fig. 5). It gives a resistance of $286.65 \mathrm{M} \Omega$ with a conductance of $3.48 \mathrm{nS}$.

The same ohmic behavior and in the same order of resistance value were obtained for the other samples, although in some cases with small electrical oscillations. For example Fig. 5 (b) shows the I-V response with electrical oscillations obtained form an arbitrary sample. In this case, the higher resistance value is a signal of higher surface scattering of the electrons within the gold crystals. This could be probably enhanced by the $\mathrm{Cu}$ electrodes oxidation, since the extremely high surface to volume ratio of the electrodes makes them more sensitive to oxidation. Another possible reason could be the oscillations are caused due to poor connection between Au crystals. This has been observed in the electrical characterization of different elements; for example, $\mathrm{VnO}_{5}$ [24], $\mathrm{Au}$ [25], Mo [26] and $\mathrm{Bi}$ [27]. In all of them, it has been quite difficult to achieve a reliable contact with resistances of the order of only ohms. Samples that present diffusive electron transport and are not ohmic conductors could possibly increase the difficulty of studying the electrical responses from external systems due to the low sensitivity of these microwires. 

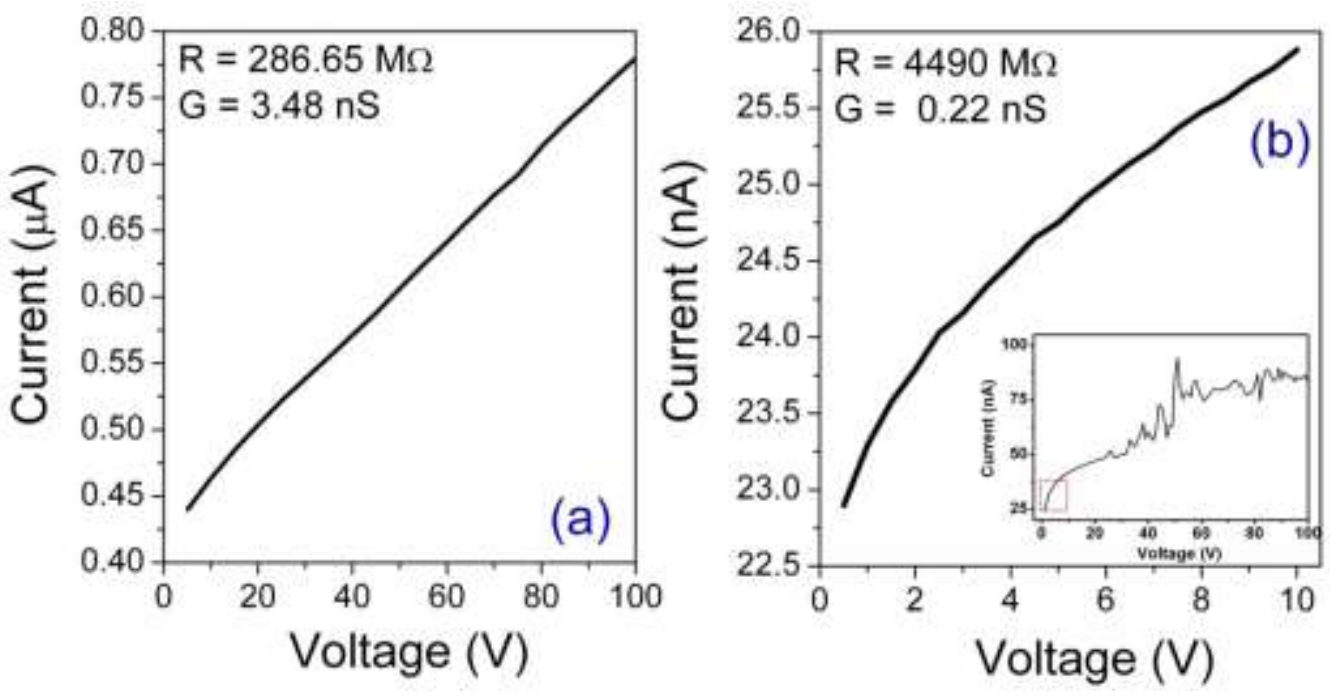

Figure 5: a) I-V measurement of the sample after gold deposition. The calculated resistance is $286.65 \mathrm{M} \Omega$ and the dimensions of the gold microwire bridge is $142,38 \mu \mathrm{m}(L)$. b) I-V characteristic of a typical sample obtained by homemade lithographic technique and after electroless gold deposition (scan voltage up to $10 \mathrm{~V}$ ). Inset: Scan voltage up to100V.

\section{CONCLUSIONS}

We have successfully demonstrated a homemade lithographic technique for the production of $\mathrm{Cu}$ electrodes with gap separation as less as $100 \mu \mathrm{m}$. This technique is cheap and does not require the use of sophisticate apparatuses. Moreover, we have achieved electroless deposition of $\mathrm{Au}$ on the $\mathrm{Cu}$ surface electrodes forming gold crystals bridges. This happened in spite of the relative wide gap of the electrodes. The system presents ohmic behavior with a high resistance and the copper microelectrodes have a short oxidation time. Eventually we observed other non-ohmic signals like electrical oscillations in the devices after applying high voltages which are probably caused by the $\mathrm{Cu}$ electrodes oxidation and due to possible poor connection between $\mathrm{Au}$ crystals.

\section{ACKNOWLEDGEMENTS}

This work was supported by the Brazilian science agencies Coordenação de Aperfeiçoamento de Pessoal de Nível Superior (capes), the Conselho Nacional de Desenvolvimento Científico e Tecnólogico (CNPq) and the Fundação de Amparo à Ciência e Tecnologia do Estado de Pernambuco (FACEPe). The work in Japan was supported by the Japan Society for the Promotion of Science (JSPS) and a collaborative research project of the Materials and Structures Laboratory from the Tokyo Institute of Technology. The work in Peru was supported by the Ministry of Production (FINCYT Project ECIP-1-P-069-14). The work in Cambridge was supported by the Engineering and Physical Sciences Research Council (EPSRC). The authors are indebted to Dr. Pedro Linhares Filho for his help during the electrical measurements.

\section{BIBLIOGRAPHY}

[1] LI, T., HU, W., ZHU, D., “Nanogap Electrodes”,Advanced Materials, v. 22, n.2, pp. 286-300, January 2010.

[2] FINOT, E., BOURILLOT, E., MEUNIER-PREST, R., et al, "Performance of inter digitated nanoelectrodes for electrochemical DNA biosensor", Ultramicroscopy, v. 97, n. 1-4, pp. 441-449, October, 2003. 
RODRIGUEZ MARTINEZ, M.A.; FELIX, L.L.;VALLADARES, L.S.; BUSTAMANTE DOMINGUEZ, A.; HUAMANI COAQUIRA, J.A.; ALVARADO, J.R.; MAJIMA, Y.; AGUIAR, J.A.; BAMES, C. revista Matéria, v.21, n.1, pp. 252 - 259 , 2016.

[3] HAGUET,V., MARTIN,D., MARCON,L., et al., "Combined nanogap nanoparticles nanosensor for electrical detection of biomolecular interactions between polypeptides", Applied Physics Letter, v. 84, n. 7, pp. 1213-1215, February, 2004.

[4] ZHOU, C., MULLER, C. J., DESHPANDE, M. R., et al., "Microfabrication of a mechanically controllable break junction in silicon", AppliedPhysicsLetter, v. 67, n. 8, pp. 1160-1162, August, 1995.

[5] PARK, H., LIM, A. K. L., ALIVISATOS, A. P., et al., "Fabrication of metallic electrodes with nanometer separation by electromigration”, Applied Physics Letter, v. 75, n. 2, pp. 301-303, July, 1999.

[6] SANTOS VALLADARES, L., BUSTAMANTE DOMÍNGUEZ, A., et al., "Attaching thiolated superconductor grains on gold surfaces for nanoelectronics application", Japanese Journal of Applied Physics, v. 49, n. 9R, pp. 093102, September, 2010.

[7] SANTOS , L., BUSTAMANTE, A., AGUIAR, J., et al., "Reorientation response of magnetic microspheres attached to gold electrodes under an applied magnetic field", Brazilian Journal of Physics, v. 43, n. 4, pp. 2092013, May, 2013.

[8] SCHUKFEH, M., STORM, K., HANSEN, A., et al., "Formation of nanogaps in InAs nanowires by selectively etching embedded InP segments”, Nanotechnology, v. 25, n. 46, p. 465306, October 2014.

[9] CUI, A., LIU, Z., DONG, H., et al. "Nanogap Electrodes: Single Grain Boundary Break Junction for Suspended Nanogap Electrodes with Gapwidth Down to 1-2 nm by Focused Ion Beam Milling", Advanced Materials,. v. 27, n. 19, p. 3095, May, 2015.

[10] NAGASE, T., "Nano-gap Electrodes Developed Using Focused Ion Beam Technology", Handbook of Manufacturing Engineering and Technology, pp. 1513-1528, 2014

[11] REICHERT, R., OCHS, R., BECKMANN, D., et al., "Driving current through single organic molecules", Physical Review Letters, v. 88, n. 17, pp. 1768041-1768044, April, 2002.

[12] SANTOS, L., LEON, L., BUSTAMANTE, A., et al., "Controlled electroplating and electromigration in nickel electrodes for nanogap formation”, Nanotechnology, v. 21, n. 445304, pp. 1-8, October, 2010.

[13] ITO, M., YAGI, M., MORIHARA, K., et al., "Simultaneous fabrication of nanogap electrodes using field-emission-induced electromigration”, Journal of Applied Physics, v. 118, pp. 0143011 - 0143015, July, 2015.

[14] LI, C. Z., HE, H. X., TAO, N. J., "Quantized tunneling current in the metallic nanogaps formed by electrodeposition and etching”, Applied Physics Letter, v. 77, n. 24, pp. 3995-3997, December, 2000.

[15] MORPURGO,A. F., MARCUS,C. M., ROBINSON,D. B., "Controlled fabrication of metallic electrodes with atomic separation”, Applied Physics Letter, v. 74, n. 14, pp. 2084-2086, April, 1999.

[16] SANTOS, L., BUSTAMANTE, A., MITRELIAS, T., et al., Fabrication of Nanogap Electrodes by Electroless- and Electrodeposition, Pan Stanford Publishing Pte. Ltd., 2012.

[17] YASUTAKE, Y., KONO, K., KANEHARA, M., et al.,"Simultaneous fabrication of nanogap gold electrodes by electroless gold plating using a common medical liquid", Applied Physics Letter, v. 91, n. 20, pp. 2031071-2031073, November, 2007.

[18] SCHLESINGER, M., PAUNOVIC, M., Modern electroplating, 5 ed., New Jersey, John Wiley\& Sons Inc., 2010.

[19] Ah, C. S., Yun, Y. J. Lee, J. S., et al, "Fabrication of integrated nanogap electrodes by surface-catalyzed chemical deposition", Applied Physics Letter, v. 88, n. 13, pp. 1331161-1331163, March, 2006.

[20] SANTOS, L., HURTADO, D., BUSTAMANTE, A., et al., "Crystallization and electrical resistivity of $\mathrm{Cu}_{2} \mathrm{O}$ and $\mathrm{CuO}$ obtained by thermal oxidation of $\mathrm{Cu}$ thin films on $\mathrm{SiO}_{2} / \mathrm{Si}$ substrates", Thin Solid Films, v. 520 , n. 20, pp. 6368-6374, August, 2012

[21] Bernard Dennis Cullity, Elements of x-ray diffraction, 3 ed., London, Prentice-Hall, Prentice-Hall International, Upper Saddle River, NJ, 2000.

[22] WEISSBERGER, A., LUVALLE, J. E., "Oxidation processes. XVII. The autoxidation of ascorbic acid in the presence of copper", Journal of the American Chemical Society, v. 66, n. 5, pp. 700-705, May, 1944.

[23]Galperin, Y. M. Quantum transport lecture notes, 1 ed., Lund University, pp. 15, November, 1998.

[24] Muster, J., Kim, G. T., Krstic, V., Park, J. G., Park, Y. W., Roth, S., Burghard, M., "Electrical transport through individual vanadium pentoxide nanowires" Advanced Materials, v. 12, n. 6, pp. 420-424, March, 2000. 
RODRIGUEZ MARTINEZ, M.A.; FELIX, L.L.;VALLADARES, L.S.; BUSTAMANTE DOMINGUEZ, A.; HUAMANI COAQUIRA, J.A.; ALVARADO, J.R.; MAJIMA, Y.; AGUIAR, J.A.; BAMES, C. revista Matéria, v.21, n.1, pp. 252 - 259 , 2016.

[25] SMITH, P. A., NORDQUIST, C. D., JACKSON, T. N., MAYER, T. S., MARTIN, B. R., MBINDYO, J., AND MALLOUK, T. E., "Electric-field assisted assembly and alignment of metallic nanowires", Applied Physics Letter, v. 77, n. 9, pp. 1399-1401, August, 2000.

[26] Zach, M. P., Ng, K. H., Penner, R. M., "Molybdenum nanowires by electrodeposition”,Science, v. 290, pp. 2120-2123,December, 2000.

[27] ZHANG, Z., SUN, X., DRESSELHAUS, M. S., YING, J. Y., HEREMANS, J., "Electronic transport properties of single-crystal bismuth nanowire arrays", Physical Review B, v. 61, n. 7, pp. 4850-4861, February, 2000. 